\title{
Oxidation of differently prepared Al-Mg alloy powders in oxygen
}

\author{
Hongqi Nie, Mirko Schoenitz, Edward L. Dreizin \\ New Jersey Institute of Technology, Newark, NJ 07103
}

\begin{abstract}
Powders of both commercial atomized spherical Al-Mg alloy and mechanically alloyed Al-Mg were oxidized in oxygen using thermo-gravimetry (TG). For both powders, the $\mathrm{Al} / \mathrm{Mg}$ mass ratio was equal to 1 . Fully and partially reacted powders were recovered and characterized using scanning electron microscopy and x-ray diffraction. Voids grow within oxidized alloy particles for both atomized and mechanically alloyed powders. Results were interpreted accounting for the measured particle size distribution for the spherical powder and distributing the TG-measured weight gain among the individual particle size bins. The reaction interfaces were always located at the internal surface of the oxide shell as determined by matching the oxidation dynamics for particles with the same sizes but belonging to powders with different particle size distributions. Thus, the reaction is always rate limited by inward diffusion of oxygen ions through the growing oxide shell. Two oxidation stages were identified for both materials. Both $\mathrm{Al}$ and $\mathrm{Mg}$ oxidize during both observed oxidation stages. The second oxidation stage is caused by formation of the spinel phase, most likely occurring at a threshold temperature. In the present measurements, the step in the oxidation rate, or switch between the oxidation stages, occurs when the oxide shell grows above a certain thickness of approximately $1.5 \mu \mathrm{m}$. The apparent activation energy during the first oxidation stage energy changes during the first oxidation stage suggesting that more than one reaction occur in parallel, e.g., causing formation of $\mathrm{MgO}$ and amorphous alumina. For the second oxidation step, controlled by diffusion of oxygen through spinel layer, the activation energy remains nearly constant around $185 \mathrm{~kJ} / \mathrm{mol}$.
\end{abstract}

Keywords: intermetallic; oxidation; kinetics; thermal analysis.

Corresponding author: Edward L. Dreizin, dreizin@ @jit.edu

\section{INTRODUCTION}

Various Al-Mg alloys find multiple applications in structural materials [1, 2], for hydrogen storage[3], and as components of energetic formulations [4-6]. Most of the published work on oxidation of such alloys deal with compositions with small concentrations of $\mathrm{Mg}$, varied from less than 1 to 5\% [7-9]. For such materials, it was observed that the oxide includes different layers, with $\mathrm{MgO}$ typically observed on top of $\mathrm{MgAl}_{2} \mathrm{O}_{4}$ and/or $\mathrm{Al}_{2} \mathrm{O}_{3}$. At the same time, alloys with much higher concentrations of $\mathrm{Mg}$ are of interest for propellants, explosives, and pyrotechnics [10-13]. Oxidation of such high-Mg content materials is not well understood. In Ref. [14], oxidation of an $\mathrm{Al}_{3} \mathrm{Mg}_{2}$ alloy was considered. The reaction was observed to proceed 
in three stages with three distinct rates: an $\mathrm{MgO}$ layer was reported to form initially; then $\mathrm{MgAl}_{2} \mathrm{O}_{4}$ oxide was produced, which finally cracked, leading to the third oxidation stage. A general rule used to estimate the tendency of metals to continuously oxidize, the PillingBedworth ratio [15] of the molar volumes of oxide and metal is close to unity for high-Mg aluminum alloys, and is therefore not expected to be particularly predictive for oxidation behavior. Further, kinetic details enabling the quantitative description of these reactions are not available. Such descriptions are important for reactive materials for prediction of both aging and ignition behaviors of the relevant compositions. Recently, thermo-analytical studies were used to clarify reaction mechanisms and describe them quantitatively for both $\mathrm{Al}[16,17]$ and $\mathrm{Mg}[18]$ powders. Here, a similar experimental approach and data processing techniques are applied to characterize high temperature oxidation in Al-Mg alloys with equal mass fractions of aluminum and magnesium. The objectives are to identify the interface for heterogeneous oxidation reactions and describe reaction mechanisms and rates quantitatively. The experiments performed with two types of Al-Mg alloys prepared by different techniques, and thus having distinct initial structures and morphologies.

\section{EXPERIMENTAL}

\subsection{Materials}

Two Al-Mg alloy powders with Al/Mg mass ratio of 50:50 were used in thermo-gravimetric (TG) experiments. An atomized spherical alloy, -270 Mesh was provided by Valimet Inc. A mechanically alloyed powder was prepared at NJIT as described in detail elsewhere [19-21]. Briefly: starting materials for the mechanically alloyed powder were elemental powders of Al (Atlantic Equipment Engineers, 99.8\% pure, -325 Mesh) and Mg (Alfa-Aesar, 99.8\% pure, -325 Mesh). Mechanical alloying was performed using a Retsch PM-400 MA planetary mill operated at $350 \mathrm{rpm}$. Powder mass load was $30 \mathrm{~g}$ per vial; $9.5 \mathrm{~mm}$-diameter hardened steel balls served as milling media. The ball to powder mass ratio was 10; the milling time was 2 hours. Each vial was filled with $50 \mathrm{mg}$ of hexane used as a process control agent.

Scanning electron microscope (SEM) images for both Al-Mg alloy powders are shown in Fig. 1. The particles have roughly spherical shapes for atomized Al-Mg alloys. Mechanically alloyed powder particles have characteristic angular shapes; they also are noticeably coarser than the atomized powders. 

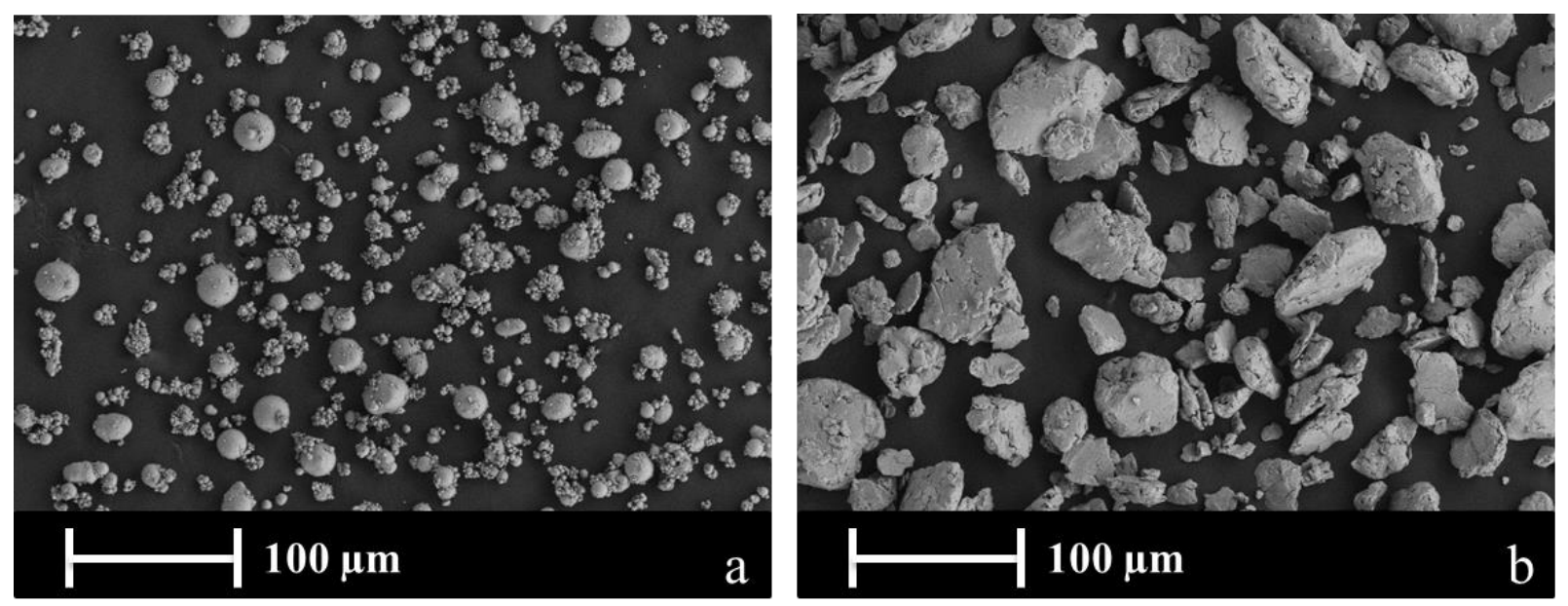

Figure 1. Backscattered SEM images for Al-Mg powders: atomized spherical alloy (a) and mechanically alloyed powder (b).

For detailed TG measurements described below, the spherical atomized alloy powder was split into two fractions with different but partially overlapping particle size distributions. The powder was passed through a 550 Mesh $(25 \mu \mathrm{m}$ opening $)$ sieve. The particle size distributions for both obtained size fractions were measured using a Beckman-Coulter LS230 Enhanced Particle Analyzer as shown in Fig. 2. These measured particle size distributions were directly used to process the TG measurements for the atomized alloy powder. The TG measurements for the mechanically alloyed powder were interpreted qualitatively and did not rely on the particle size distribution measurements.

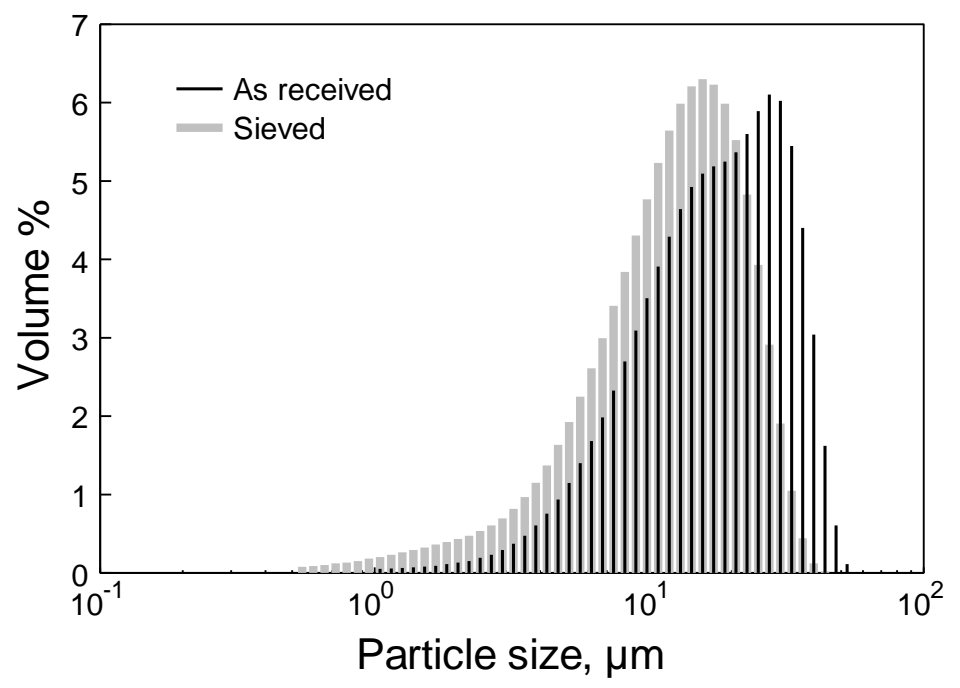

Figure 2. Particle size distributions for coarse (as received) and fine (sieved) fractions of the spherical atomized $\mathrm{Al}-\mathrm{Mg}$ alloy powder used in experiments. 


\subsection{Oxidation experiments}

Both Al-Mg powders were oxidized in an oxygen/argon mixture using a Netzsch STA409PC/PG thermal analyzer with a thermogravimetric sample carrier. The customized furnace used in experiments provided the oxidizer flow from the top of the furnace down to the sample. This flow pattern helped to oxidize and condense evaporating magnesium directly in the sample holder. Magnesium evaporation and deposition of the oxide elsewhere in the furnace presented a serious experimental problem in preliminary experiments, when a regular furnace was used, in which the oxidizing gas was rising from the bottom up.

In these experiments, argon was introduced as both a protective gas surrounding the thermobalance and as a carrier gas for oxygen/argon oxidizing mixture; the respective flow rates of argon were 90 and $20 \mathrm{~mL} / \mathrm{min}$. The oxygen flow rate was $10 \mathrm{~mL} / \mathrm{min}$ so that oxygen comprised $30 \%$ of gas supplied to the sample. The powders were held on a $17-\mathrm{mm}$ diameter flat corundum sample holder and heated up to $800{ }^{\circ} \mathrm{C}$. Heating rates varied from 2 to $20^{\circ} \mathrm{C} / \mathrm{min}$ in different experiments.

Fully and partially oxidized powders were recovered and examined using a scanning electron microscope (LEO 1530 Field Emission SEM); their compositions were characterized using x-ray diffraction (XRD) using a PANalytical Empyrean diffractometer. The diffractometer was operated at $45 \mathrm{kV}$ and $40 \mathrm{~mA}$ using unfiltered $\mathrm{Cu} \mathrm{K} \alpha$ radiation $(\lambda=1.5438 \AA)$.

\section{RESULTS AND DISCUSSION}

\subsection{Phases and morphologies formed upon oxidation}

Initial oxidation TG measurements were performed for both atomized and mechanically alloyed powders at a fixed heating rate of $5{ }^{\circ} \mathrm{C} / \mathrm{min}$. The resulting TG traces are shown in Fig. 3. A characteristic, two-stage oxidation pattern is observed for both materials. For the atomized powder, an appreciable oxidation begins above $350^{\circ} \mathrm{C}$. For mechanically alloyed powder, the mass increase becomes detectable above $400{ }^{\circ} \mathrm{C}$. For both materials, reaction accelerates substantially around $500{ }^{\circ} \mathrm{C}$. The second oxidation stage begins above ca. $530^{\circ} \mathrm{C}$, when the rate of oxidation becomes slower. It remains nearly constant for the mechanically alloyed powder at higher temperatures. An additional acceleration in the oxidation rate is observed for the atomized powder at approximately $600{ }^{\circ} \mathrm{C}$.

Open circles in Fig. 3 show the temperatures, from which each powder was quenched and recovered for SEM and XRD analyses. These temperatures were 450,520 , and $650{ }^{\circ} \mathrm{C}$ for the atomized powder and 520 and $800{ }^{\circ} \mathrm{C}$ for the mechanically alloyed powder; they were selected to observe possible differences in the oxidation products formed at different reaction stages. 


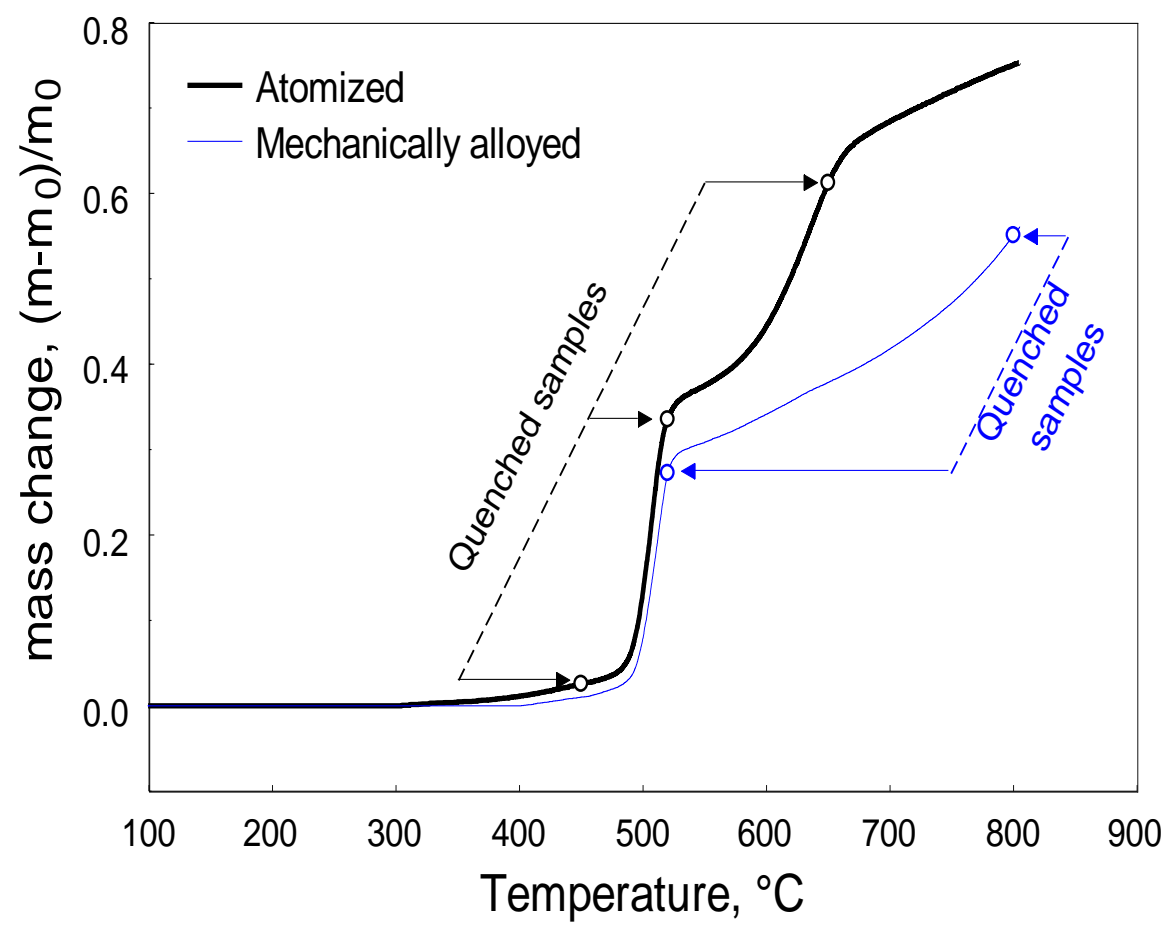

Figure 3. TG traces for the atomized spherical Al-Mg alloys (black) and mechanically alloyed Al-Mg powder (blue) in oxygen at $5^{\circ} \mathrm{C} / \mathrm{min}$.

SEM images of the partially oxidized powders are shown in Figs. 4 and 5 for atomized and mechanically alloyed powders, respectively. The atomized powder recovered at $450{ }^{\circ} \mathrm{C}$, retains its spherical shape; however, the particle surface is not as smooth as for the original material. Minor surface depressions are noticed, which may indicate shrinkage of the thermally expanded particles. For the powder recovered from higher temperatures, as shown in Fig. 4 (b) and (c), many broken hollow particles are observed. While breakage of the particles was most likely caused by the handling of the powder samples transferred to the SEM sample holder, as shown earlier [17], the hollow shells were clearly formed during oxidation. No qualitative difference was observed between samples shown in Figs. 4 (b) and (c).

For the partially oxidized mechanically alloyed powders, the changes in the surface morphology upon oxidation were more noticeable as shown in Fig. 5 (compare to the as prepared powder, Fig. 1 (b)). In addition to multiple fine crystallites formed on the surface of particles shown in Fig. 5, formation of hollow structures is also observed, qualitatively similar to those seen in Figs. 4 (b) and (c). 


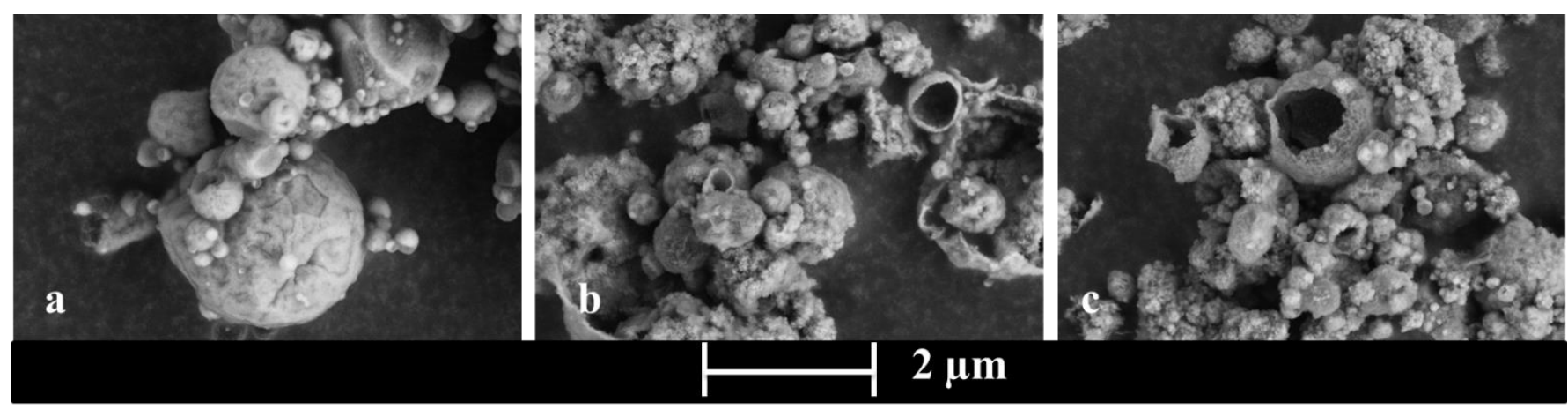

Figure 4. SEM images of partially oxidized atomized powder particles recovered from $450{ }^{\circ} \mathrm{C}$ (a), $520^{\circ} \mathrm{C}(\mathrm{b})$ and $650{ }^{\circ} \mathrm{C}(\mathrm{c})$.
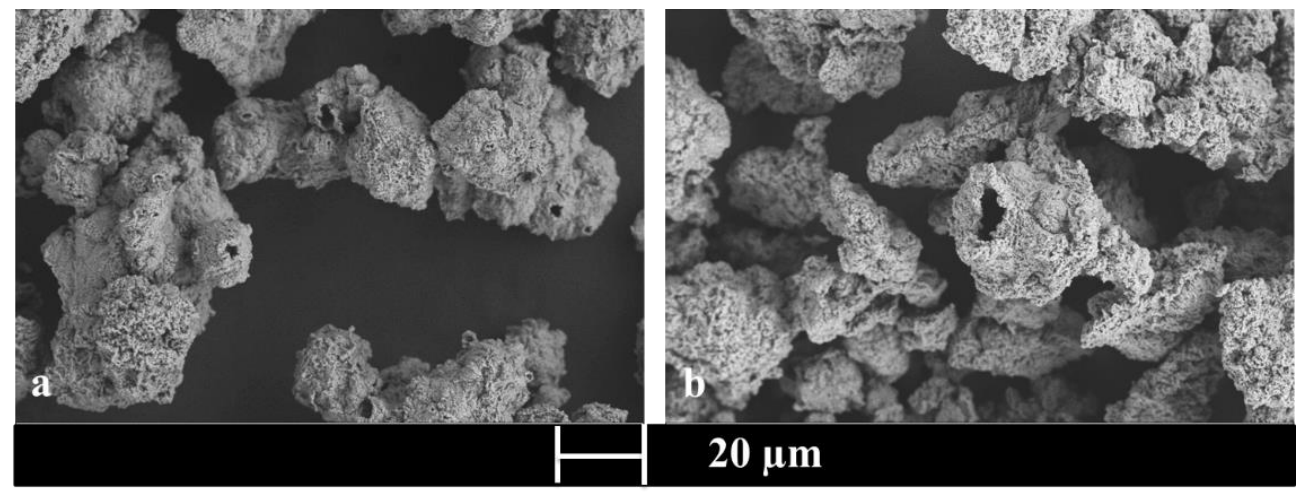

Figure 5. SEM images of partially oxidized mechanically alloyed powder particles recovered $520{ }^{\circ} \mathrm{C}$ (a) and $800{ }^{\circ} \mathrm{C}(\mathrm{b})$.

Results of the XRD analyses for partially oxidized samples of the atomized alloy are shown in Fig. 6. At $450{ }^{\circ} \mathrm{C}$, the sample mostly comprises an $\mathrm{Al}_{12} \mathrm{Mg}_{17}$ intermetallic phase. Only small amounts of $\mathrm{MgO}$ are detectable. At $520{ }^{\circ} \mathrm{C}$, strong peaks of both $\mathrm{MgO}$ and elemental $\mathrm{Al}$ appear. At $650{ }^{\circ} \mathrm{C}$, peaks of $\mathrm{MgO}$ remain nearly unchanged. Peaks of elemental Al become much weaker and strong peaks of the spinel group, $\mathrm{MgAl}_{2} \mathrm{O}_{4}$ appear.

XRD patterns for partially oxidized samples of the mechanically alloyed powder are shown in Fig. 7. Note that the as-prepared material was characterized by XRD earlier [19]. Unlike atomized powder, comprising the intermetallic $\mathrm{Al}_{12} \mathrm{Mg}_{17}$, the pattern for the mechanically alloyed powder was dominated by the broadened peaks of elemental $\mathrm{Al}$ and $\mathrm{Mg}$, with relatively minor peaks of the intermetallic. For the sample recovered at $520{ }^{\circ} \mathrm{C}$, peaks of elemental $\mathrm{Al}$ and $\mathrm{MgO}$ become strong, similar to that observed in Fig. 6 for the atomized powder. Also similar to the atomized powder, peaks of spinel, $\mathrm{MgAl}_{2} \mathrm{O}_{4}$ become well-visible for the sample recovered from $800{ }^{\circ} \mathrm{C}$. 


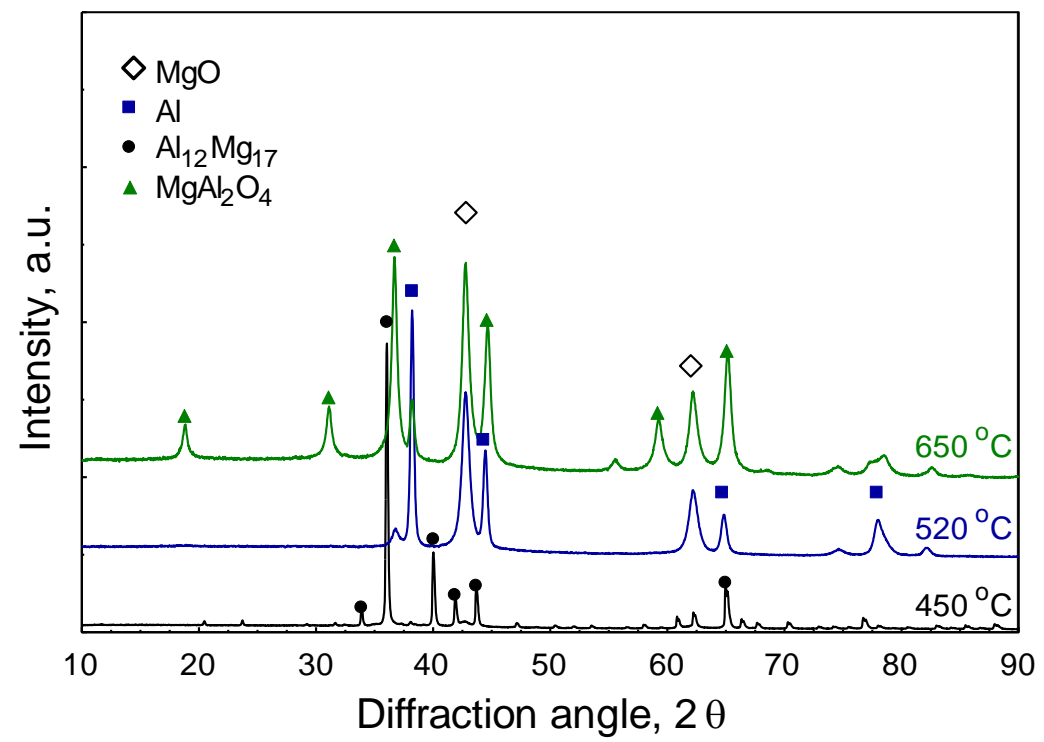

Figure 6. XRD pattern for the reaction products of spherical Al-Mg alloys powder quenched and recovered at $450{ }^{\circ} \mathrm{C}, 520^{\circ} \mathrm{C}$ and $650{ }^{\circ} \mathrm{C}$.

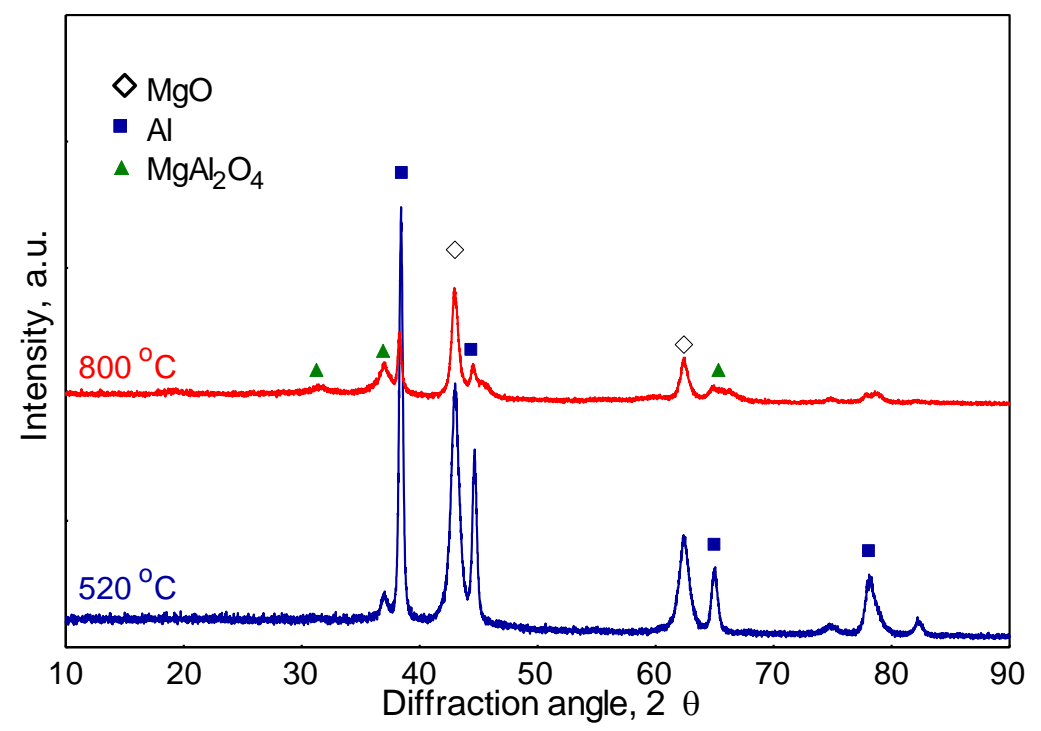

Figure 7. XRD pattern for the reaction products of mechanically alloyed $\mathrm{Al}-\mathrm{Mg}$ powder quenched and recovered at $520^{\circ} \mathrm{C}$ and $800{ }^{\circ} \mathrm{C}$.

XRD results for both powders consistently indicate formation of $\mathrm{MgO}$ during the first stage of oxidation. The second stage is accompanied by formation of the ternary $\mathrm{MgAl}_{2} \mathrm{O}_{4}$ spinel. It is, therefore, tempting to interpret the present observations as suggesting a selective oxidation of magnesium during the first oxidation stage, and oxidation of both aluminum and magnesium during the stage two. However, it is also possible that oxidation of aluminum occurs during 
stage one as well, producing amorphous alumina, undetectable by XRD. Both possibilities will be examined below.

If a general Al-Mg alloy is expressed as $\mathrm{Al}_{a} \mathrm{Mg}_{b}$ where $a+b=1$, then the composition of Al-50 wt- $\% \mathrm{Mg}$ used in this study corresponds to $a=0.47$ and $b=0.53$. The complete oxidation of this material yields $\mathrm{MgO}$ and $\mathrm{MgAl}_{2} \mathrm{O}_{4}$. The global reaction is:

$$
\begin{aligned}
& A l_{\mathrm{a}} M g_{b}+\frac{\left(2 \xi_{M g}-3 \xi_{A l}\right) b+3 \xi_{A l}}{4} O_{2} \longrightarrow \\
& \left(\xi_{M g} b-\xi_{A l} \frac{1-b}{2}\right) M g O+\xi_{A l} \frac{1-b}{2} M g A l_{2} O_{4}+c A l_{\left(1-\xi_{A l}\right) a / c} M g_{\left(1-\xi_{M g}\right) b / c}
\end{aligned}
$$

where the fractions of oxidized $\mathrm{Mg}$ and $\mathrm{Al}$ are expressed with the parameters $\xi_{\mathrm{Mg}}=\left(n_{\mathrm{MgO} \mathrm{O}}+n_{\mathrm{MgAl}_{2} \mathrm{O}_{4}}\right) / b$ and $\xi_{\mathrm{Al}}=2 n_{\mathrm{MgAl}_{2} \mathrm{O}_{4}} /(1-b)$ using the stoichiometric coefficients of the products, $n_{\mathrm{MgO}}$ and $n_{\mathrm{MgAl}_{2} \mathrm{O}_{4}}$, and $c=1-(1-b) \xi_{\mathrm{Al}}-b \xi_{\mathrm{Mg}}$. Overall reaction progress as derived from the TG experiments is defined as the relative mass change $\Delta m / m_{0}$. Considering that formation of amorphous alumina is possible, it is not known a priori how either oxide fraction varies with overall reaction progress. It is interesting that the most strictly segregated case, the complete oxidation of $\mathrm{Mg}$ up to $\xi_{M g}=1$ while the $\mathrm{Al}$ component remains unoxidized with $\xi_{A l}=0$, corresponds to the formation of 0.53 moles of $\mathrm{MgO}$, and a mass change of $33.17 \%$. Cursory examination of the TG measurements shown in Fig. 3 suggests that the first oxidation step near $500{ }^{\circ} \mathrm{C}$ can be entirely and satisfactorily explained by this selective oxidation scheme. However, in the following analysis tracking oxidation of particles of different sizes, this explanation will be shown to be incorrect.

\subsection{TG data processing and location of the heterogeneous reaction interface}

When a powder with different particle sizes is oxidized in a TG experiment, the mass can increase at different rates for particles with different sizes, particularly when the oxidation reaction occurs at the particle surface. In order to account for this, and to allow for a more meaningful interpretation of TG measurements, a methodology was developed in previous research[16-18, 22] that distributes the weight change from the TG measurements among particles of different sizes using the measured particle size distribution. This methodology was applied to the measurements for the spherical atomized powder in this study.

The heterogeneous oxidation reaction on the particle surface implies a particular geometry. Several different scenarios, characterized by the interface where new oxides form, are illustrated in Fig. 8. All scenarios lead to the formation of a void in the particle interior, as observed in 
SEM images of the partially oxidized particles. In all cases, a metallic core with an interior void is surrounded by an oxide shell, but in each individual case the available reactive interface varies differently with reaction progress.

Following the TG measurements of stepwise oxidation and the XRD observation of $\mathrm{MgO}$ as initially the only detectable product, for the purpose of splitting the TG measured weight change among particles of different sizes, it was assumed that the oxidation is strictly selective: the top panels in Fig. 8 describe oxidation of $\mathrm{Mg}$ only, producing $\mathrm{MgO}$, followed by the oxidation of the $\mathrm{Al}$ component and reaction with $\mathrm{MgO}$ yielding $\mathrm{MgAl}_{2} \mathrm{O}_{4}$ in the bottom panels in Fig. 8. This assumption affected the thickness of the oxide layer predicted to grow on each particle, because of different densities of the products formed at different reaction stages. The difference in densities of $\mathrm{MgO}\left(3.58 \mathrm{~g} / \mathrm{cm}^{3}\right), \mathrm{Al}_{2} \mathrm{O}_{3}\left(3.95 \mathrm{~g} / \mathrm{cm}^{3}\right)$, and $\mathrm{Al}_{2} \mathrm{MgO}_{4}$ (ca. $3.55 \mathrm{~g} / \mathrm{cm}^{3}$ [23]) is relatively minor, having only a weak effect on the predicted oxide thickness caused by the assumed selective oxidation sequence. In the present calculations, oxide densities were considered as functions of temperature. For $\mathrm{MgO}$, the density was calculated following experimental data presented in Ref. [24]. For $\mathrm{Al}_{2} \mathrm{O}_{3}$, date from Ref. [25] were used. For spinel, the calculations used a weighted average of respective temperature-dependent alumina and magnesia densities. Different oxidation schemes such as strict simultaneous oxidation of $\mathrm{Al}$ and $\mathrm{Mg}$ as well as different assumptions regarding densities would have given oxide thicknesses that are up to $1 \%$ different from the current values up to an estimated thickness of $0.7 \mu \mathrm{m}$, and do not reach $1.5 \%$ difference until full oxidation. More detailed considerations regarding oxide densities were therefore not pursued for the purpose of distributing the observed oxide mass over the particle size distribution.

Three possible reaction sequences were considered, referred to as Cases I, II, and III in Fig. 8. The reaction interface is shown by a bold dashed line. For Case I, oxidation for both stages one and two occur at the internal interface between the metallic core and growing oxide shell. For Case II, oxidation during stage one occurs at the internal metal-oxide interface, while the remaining oxidation takes place at the external particle surface. Finally, for Case III, both stage one and two reactions occur at the outer particle surface. In other words, for Case I, it is assumed that the oxidation rate always is limited by the inward diffusion of the oxidizer (oxygen ions). For Case II, oxidation during the first stage is limited by the inward diffusion of oxidizer, and during the second stage, it is limited by outward diffusion of metal ions. Finally, in Case III all reactions are assumed to be rate limited by outward diffusion of metal ions.

The mass gain measured in a TG experiment as a function of time or temperature for the powder sample was split among powder particle size bins:

$$
\frac{d M}{d t}=\sum_{n} \frac{d m_{n}}{d t}
$$


where $M$ is the total powder mass, $m_{n}$ is the mass of particles in an individual particle size bin, and $t$ is time. Index $n$ numbers particle size bins. Solving the diffusion equation for a spherical particle with a growing oxide shell (appropriate for any of the reaction scenarios shown in Fig. 8), and assuming that the mass fraction of the diffusing species changes from 1 to 0 across the oxide layer, one obtains:

$$
\dot{m}=4 \pi \rho D\left(\frac{1}{r_{1}}-\frac{1}{r_{2}}\right)^{-1}=4 \pi \rho D \frac{r_{1} r_{2}}{r_{2}-r_{1}}
$$

where $r_{1}$ and $r_{2}$ are inner and outer radii of the growing oxide layer, across which diffusion occurs; $\dot{m}$ is the mass flow of the diffusing species; $D$ is the diffusion coefficient (generally defined by Arrhenius kinetics), and $\rho$ is the oxide density. Thus, the measured mass uptake for each assumed reaction model was distributed proportionally to the function $N_{n} \cdot\left(\frac{r_{1} r_{2}}{r_{2}-r_{1}}\right)_{n}$ where $N_{n}$ is the number fraction of particles in each size bin $n$ as determined experimentally, and the radius-dependent factor is equivalent to the surface area at the geometric mean radius divided by the oxide layer thickness. The algorithm was applied iteratively, starting with a uniform initial oxide thickness of $2.5 \mathrm{~nm}$, and integrating the mass change of each size bin while allocating new material at the interface - inner or outer - indicated for each case in Fig. 8. The respective other, non-growing radius was allowed to change only to account for thermal expansion.

TG measurements were performed for two size fractions of the same powder (cf. Fig. 2). For each reaction mechanism shown in Fig. 8, the TG data were distributed among all particles as described above. The fundamental assumption in the processing described here is that the oxidation of particles of a given size is not affected by the oxidation of particles with different sizes, i.e. it is not relevant for the oxidation reaction of particles with this size whether they belong to a powder with a coarse, fine, wide, or narrow size distribution. To judge which case shown in Fig 8 represents the experiment most accurately, and therefore which interface location is consistent with the measurement, the oxide mass of the overlapping size bins calculated for one size distribution was compared to the one calculated for the other distribution. 


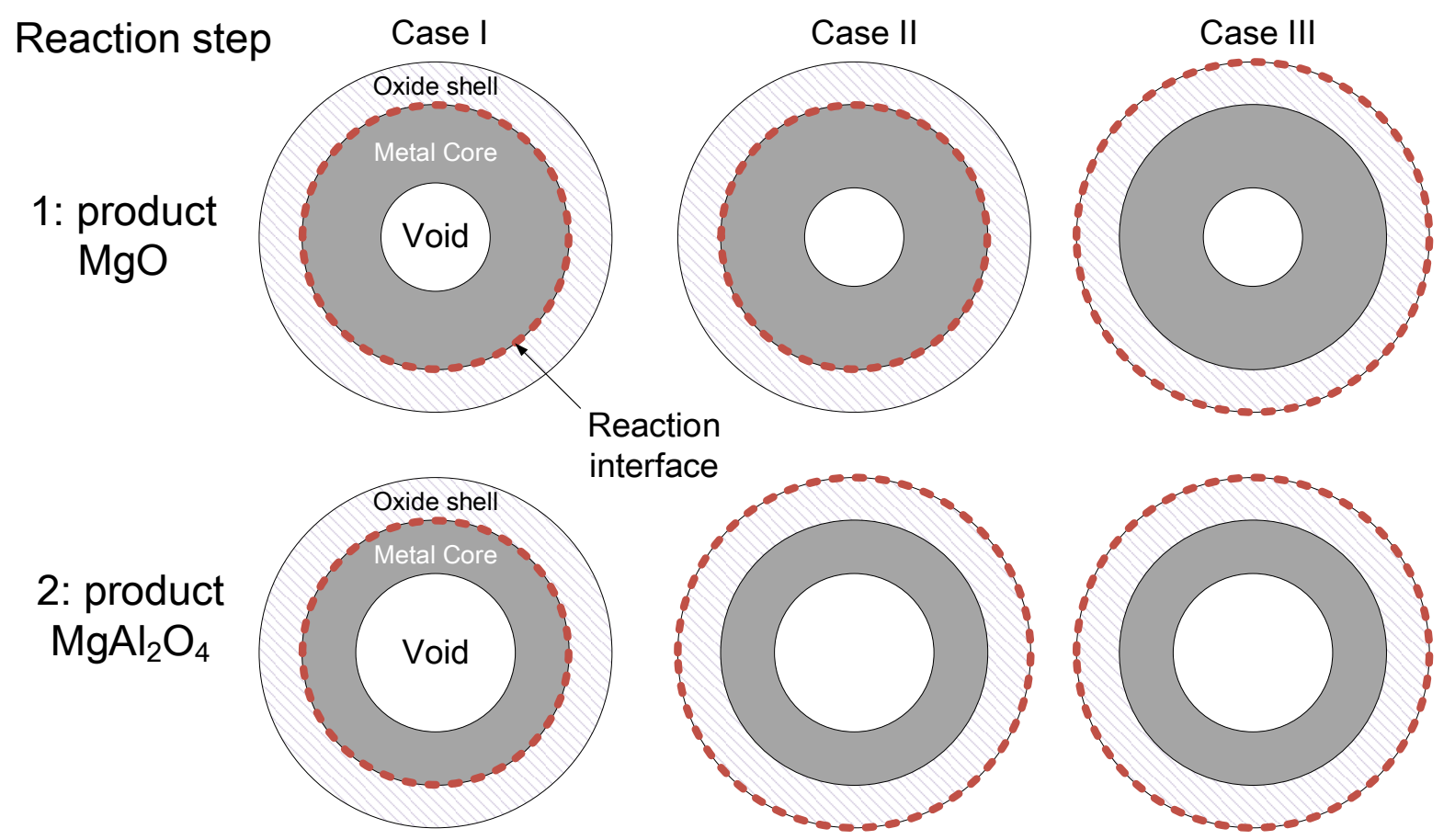

Figure 8. Schematic diagram illustrating different reaction mechanisms: Case I. Reaction always occurs at the interface between metallic core and oxide shell. Case II. During the first stage, oxidation occurs at the interface of metallic core and oxide shell. During the second stage, reaction occurs at the outer surface of the oxide shell. Case III. Reaction always occurs at the outer surface of the oxide shell.

The measured TG traces used in this analysis for both coarse (as received) and fine (sieved) powder size fractions are shown in Fig. 9. The inset in Fig. 9 expands the temperature range, for which the most significant differences were observed between mass gains for different powder size fractions. 


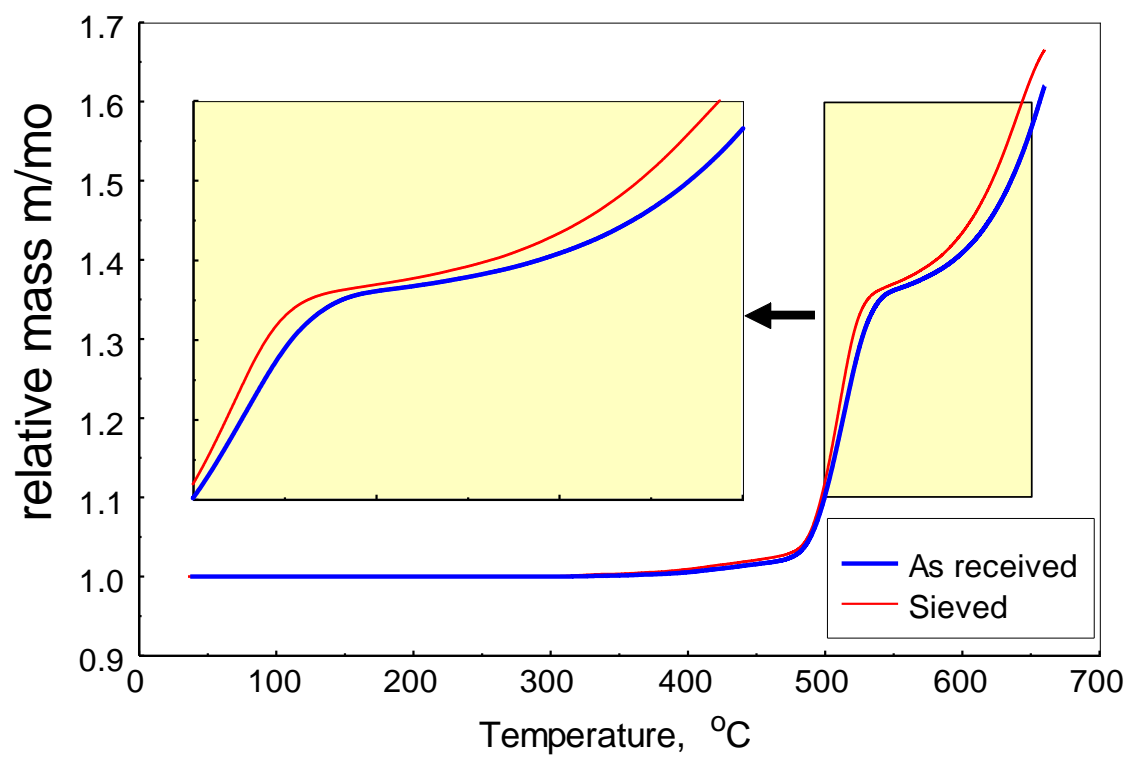

Figure 9. TG traces for two size fractions of the atomized spherical Al-Mg alloys powder oxidizing in oxygen. The heating rate was $5 \mathrm{~K} / \mathrm{min}$.

Quantitatively, following previous work [16-18], functions of mass as a function of time for all overlapping particle sizes were compared to each other using the parameter, $E r_{n}$, calculated for each particle size bin, $n$ :

$$
E r_{n}=\frac{1}{m_{n, 0} \sqrt{K}} \sqrt{\sum_{k=1}^{K}\left(m_{n, \mathrm{k}}^{\text {Coarse }}-m_{n, \mathrm{k}}^{\text {Fine }}\right)^{2}}
$$

where summation is done for all $K$ time steps for the measurements shown in Fig. 9, and $m_{n, \mathrm{k}}^{\text {Coarse }}$ and $m_{n, \mathrm{k}}^{\text {Fine }}$ are the mass changes for coarse and fine powder fractions respectively, corresponding to the $k^{\text {th }}$ time step. Parameter $E r_{n}$ quantifies discrepancy between oxidation scenarios for the particles belonging to the same size bin $n$, present in both powder samples. This parameter should be minimized for the reaction model that best describes the actual oxidation processes. Values of $E r_{n}$ implied by each model are plotted in Fig. 10 for all overlapping particle sizes of the two powder fractions. The parameter $E r_{n}$ is minimized for Case I, which assumes that both reaction steps occur at the internal interface between metallic core and oxide shell. Thus, Case I describes the reaction best for the Al-Mg alloys and oxidation of both $\mathrm{Mg}$ and $\mathrm{Al}$ is governed by the inward diffusion of oxidizer. This is similar to the oxidation mechanism identified for pure $\mathrm{Mg}$ [18], but different from the oxidation mechanism for pure $\mathrm{Al}$ [17]. We can speculate that diffusion on the oxygen sublattice is easier in the presence of $\mathrm{Mg}$, perhaps due to point defects. However, it is not clear which diffusion process actually changes substantially - diffusion on the metal or the oxygen sublattice. Future work aimed to clarify this is warranted, and could provide insights in the kinetic phenomena described in the later sections of the manuscript. 


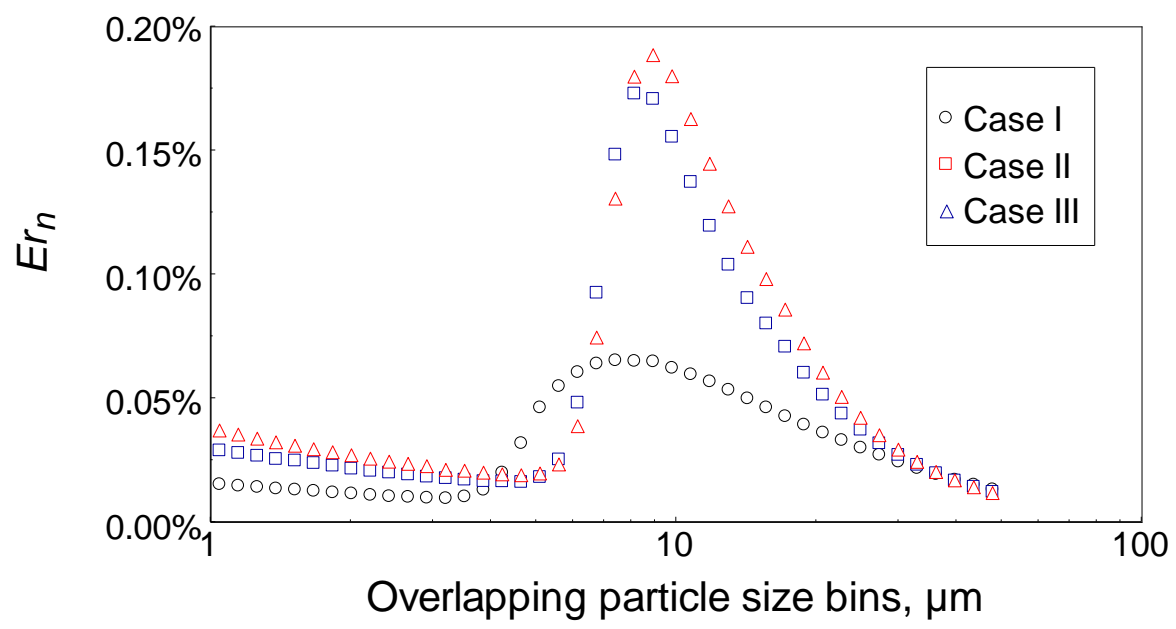

Figure 10. Cumulative discrepancy measure calculated using Eq. (4) for data on oxidation of spherical Al-Mg alloys in oxygen.

\subsection{Reaction sequence and kinetics}

TG measurements were repeated at different heating rates for the spherical atomized alloy powder, as shown in Fig. 11. The traces shift consistently to higher temperatures at greater heating rates. These measurements were used to identify the apparent activation energy of oxidation as a function of the reaction progress [26-28].

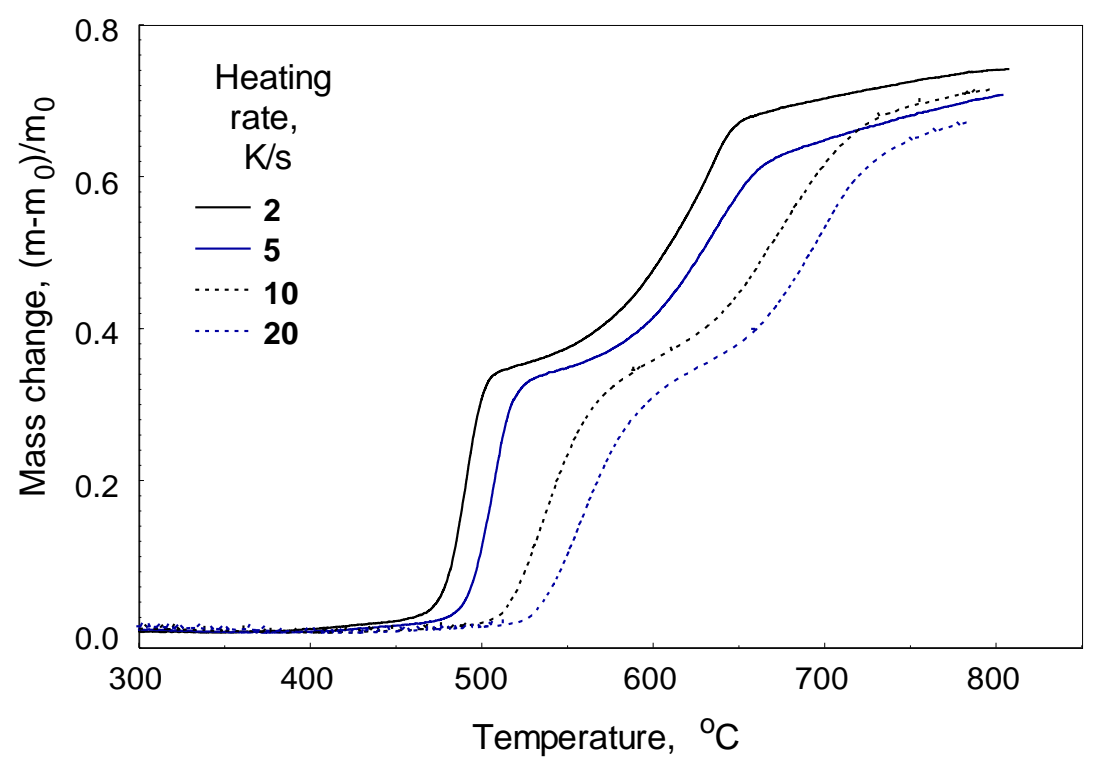

Figure 11. TG traces for atomized spherical alloys powder oxidized at different heating rates. 
A model free isoconversion method $[29,30]$ was employed. In the general case, the reaction rate is considered a function of a kinetic triplet, including activation energy, $E$, pre-exponent, $C$, and a function of reaction progress, $f(\alpha)$ :

$$
\frac{d \alpha}{d t}=C \cdot \exp \left(-\frac{E}{R_{g a s} T}\right) \cdot f(\alpha)
$$

For the isoconversion analysis the value of activation energy, $E_{\alpha}$ is determined at each given value of the reaction progress, $\alpha$, without specifying $f(\alpha)$ by minimizing the function $\Phi$ :

$$
\Phi\left(E_{\alpha}\right)=\sum_{i=1}^{n} \sum_{j \neq i}^{n} \frac{J\left[E_{\alpha}, T_{i}\left(t_{\alpha}\right)\right]}{J\left[E_{\alpha}, T_{j}\left(t_{\alpha}\right)\right]}
$$

where the subscript $\alpha$ refers to selected values of the reaction progress that were observed at time $t_{\alpha}$ and the corresponding temperature $T$, and which are associated with the activation energy $E_{\alpha}$. The sums are taken over all included experiments. The functions $J$ are integrals of the exponent of activation energy over experimental temperature over a chosen interval $\Delta \alpha$ :

$$
J\left[E_{\alpha}, T_{i}\left(t_{\alpha}\right)\right]=\int_{t_{\alpha-\alpha \alpha}}^{t_{\alpha}} \exp \left[\frac{-E_{\alpha}}{R T_{i}\left(t_{\alpha}\right)}\right] d t
$$

First, the measurements presented in Fig. 11, and representing oxidation of the entire powder sample were used. The reaction progress was defined here as the relative mass change of the entire powder, $\alpha=\left(m-m_{0}\right) / m_{0}$. The resulting activation energy is shown in Fig. 12. For the first rapid mass increase step, observed in Fig. 11 around $470-550{ }^{\circ} \mathrm{C}$ for different heating rates, the relative mass increases by approximately 0.3 , and the apparent activation energy decreases from above 200 to below $50 \mathrm{~kJ} / \mathrm{mol}$. As the reaction proceeds to the next oxidation stage, the activation energy in Fig. 12 increases stepwise and remains approximately stable around 190 $\mathrm{kJ} / \mathrm{mol}$. 


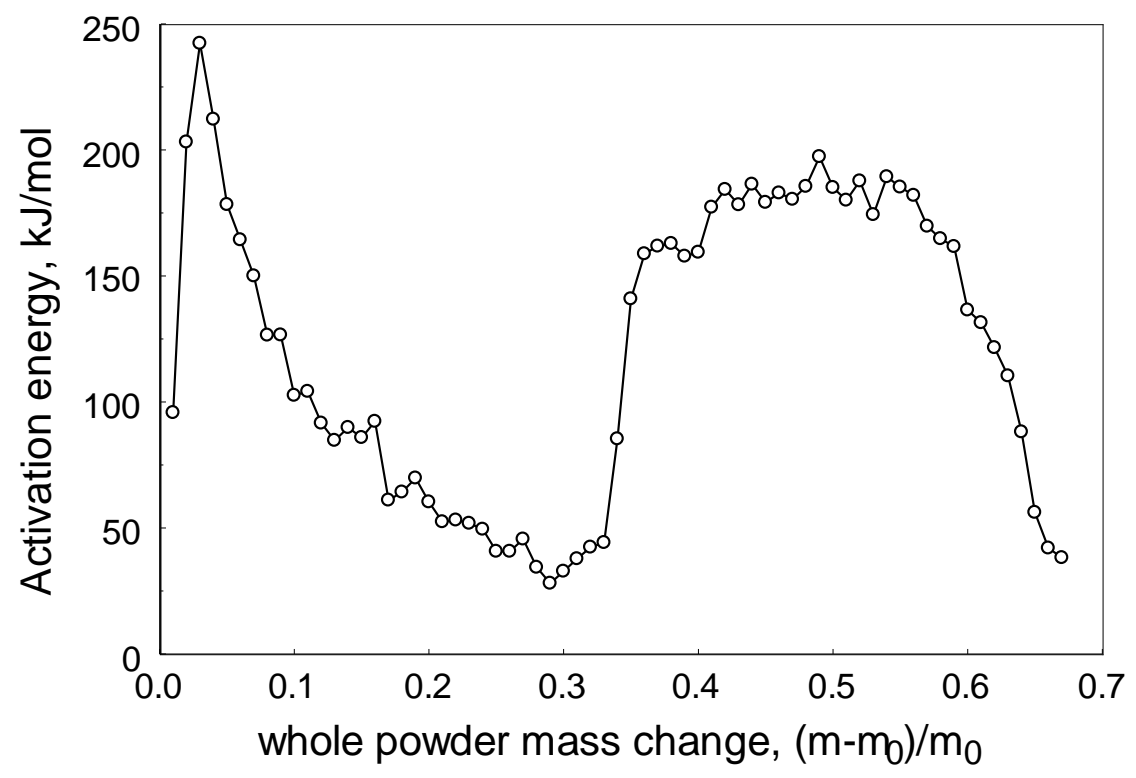

Figure 12. Apparent activation energy of oxidation for an $\mathrm{Al}-\mathrm{Mg}$ alloy powder in oxygen as a function of reaction progress defined through the sample mass change.

To understand why the apparent activation energy decreases during the initial reaction stage, consider the effect of different oxidation rates for particles of different sizes, which is unaccounted for by analysis of the whole powder.

Under the premise of early selective $\mathrm{Mg}$ oxidation, implying $\xi_{M g} \geq \xi_{A l}$, finer particles with a relatively large surface area oxidize $\mathrm{Mg}$ more quickly than coarser particles. Generally, different particle sizes have oxidized different amounts of their $\mathrm{Mg}$ content, i.e. have different values of $\xi_{M g}$. With strict segregation as assumed for the purpose of the TG data processing described in the previous section, where $\xi_{M g}$ reaches 1 before $\xi_{A l}>0$, there is a range of temperatures where $\mathrm{Al}$ oxidation in smaller particles occurs simultaneously with selective oxidation of $\mathrm{Mg}$ in larger particles. Even if the $\mathrm{Mg}$ oxidation is not strictly selective, using the whole powder to characterize reaction progress implies a mix of simultaneous reactions on the surface of particles with different relative degrees of oxidation, and therefore different compositions of the metal core regardless of geometry, oxide shell thickness, etc., and cannot give a consistent value for the activation energy

This reasoning is illustrated in Fig. 13. The solid curve shows the relative sample mass (right axis) recorded at $5 \mathrm{~K} / \mathrm{min}$. The open circles indicate the onset of $\mathrm{Al}$ oxidation $\left(\xi_{A l}=0\right)$ and the end of Mg oxidation ( $\xi_{M g}=1$ ) for each particle size bin (left axis). For the smallest particles in the size distribution, $1 \mu \mathrm{m}$, all $\mathrm{Mg}$ is consumed close to $470^{\circ} \mathrm{C}$. Thus, aluminum oxidation begins for $1-\mu \mathrm{m}$ particles just above $470{ }^{\circ} \mathrm{C}$. When the first rapid mass gain stage is finished, just above $500{ }^{\circ} \mathrm{C}$, magnesium is completely oxidized in all particles smaller than approximately 
$15 \mu \mathrm{m}$. Clearly, the apparent activation energy obtained for the entire powder shown in Fig. 12 represents different processes for different particle size bins.

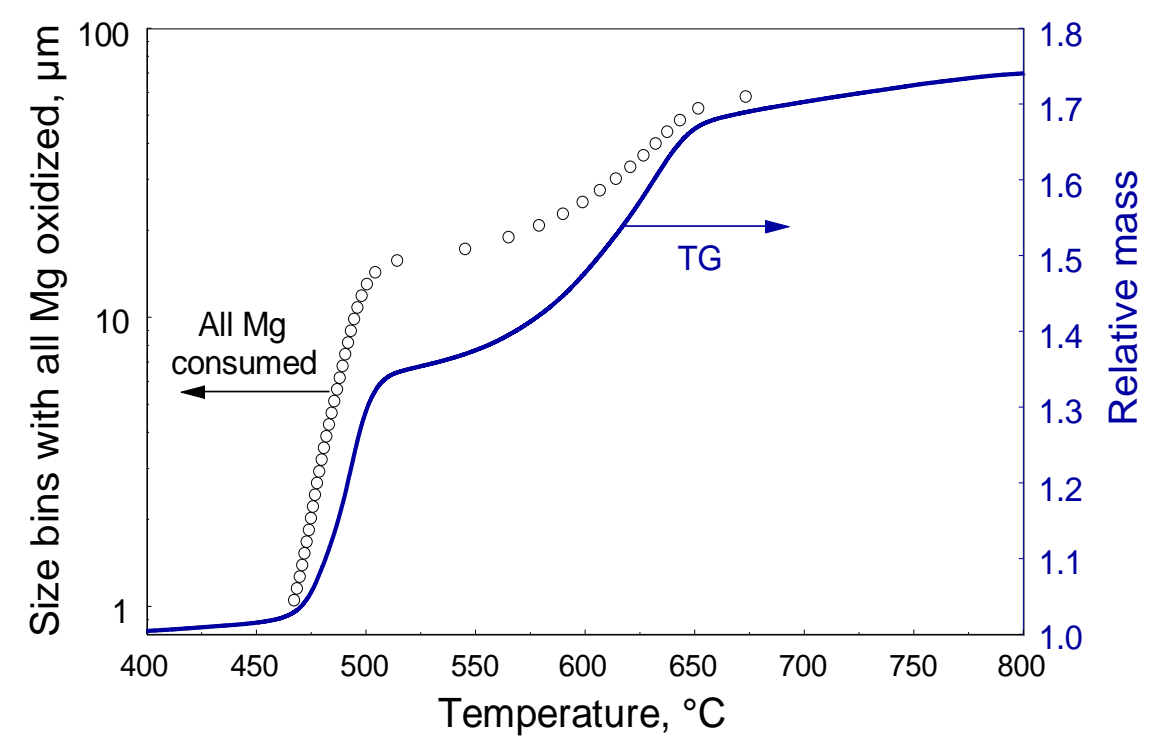

Figure 13. Size bins with all Mg selectively oxidized (open circles) vs. respective temperature and the corresponding TG trace for a spherical Al-Mg alloy in oxygen (solid curve).

The processing of TG traces described above and involving re-distribution of the measured mass gain among individual particle size bins enables one to avoid interference between different oxidation reactions occurring simultaneously for particles of different sizes.

TG traces representing the oxidation of individual particle size bins were thus obtained using the reaction mechanism shown as case I in Fig. 8. For each size bin, the isoconversion processing was applied. First, following the approach used to obtain the result shown in Fig. 12, the sample mass change was treated as reaction progress indicator. The activation energies obtained for different particle sizes are shown in Fig. 15. Qualitatively, a stepwise change in the activation energy is still observed, suggesting a step-wise change in the oxidation mechanism. The step occurs at different values of mass change for different particle sizes, suggesting that mass may not be a useful progress indicator for this reaction, and that therefore the transition does not occur at a specific degree of $\mathrm{Mg}$ oxidation, despite data from Fig. 3, which appeared consistent with strict selective $\mathrm{Mg}$ oxidation corresponding to a $33.2 \%$ mass change. The activation energy changes much after all $\mathrm{Mg}$ has been oxidized for smaller particles, and before the start of Al oxidation for larger particles. Calculations show that this situation does not qualitatively change if selective $\mathrm{Mg}$ oxidation is not strict. 


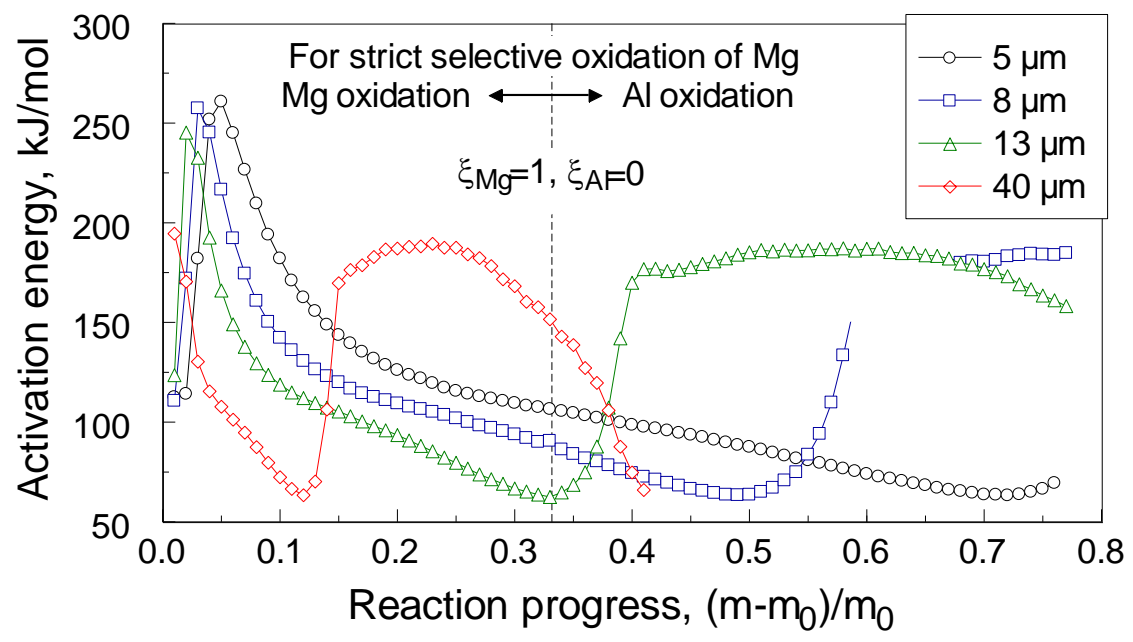

Figure 15. Apparent activation energy of oxidation for individual size bins of an Al-Mg alloy powder in oxygen as a function of reaction progress defined through the sample mass change.

The thickness of the grown oxide layer may serve as a more natural indicator of the reaction progress than the mass change. The activation energies for several individual particle size bins were thus obtained as a function of the oxide thickness as shown in Fig. 16. Interestingly, all apparent activation energy trends merge together, suggesting a fairly narrow range of oxide thicknesses, for which the reaction mechanism changes. Specifically, the transition occurs between 1.24 and $1.56 \mu \mathrm{m}$ for strictly selective $\mathrm{Mg}$ oxidation. However, since the oxide thickness is a weak function of the details of selective Mg oxidation as pointed out in section 3.2, the transition occurs near the same thickness range regardless of how strictly selective oxidation of Mg occurs. In any case, Fig. 16 suggests rather clearly that the oxide thickness is indeed a useful indicator of the reaction progress for oxidation of $\mathrm{Al} \cdot \mathrm{Mg}$ alloys.

The activation energy still changes substantially during the first oxidation stage. These changes can no longer be attributed to the interference effects between different particle sizes, however. Instead, they may indicate that oxidation proceeds through different parallel reactions. For example, formation of $\mathrm{MgO}$ and amorphous alumina occurring simultaneously and at different rates could explain the observed changes in the apparent activation energy. 


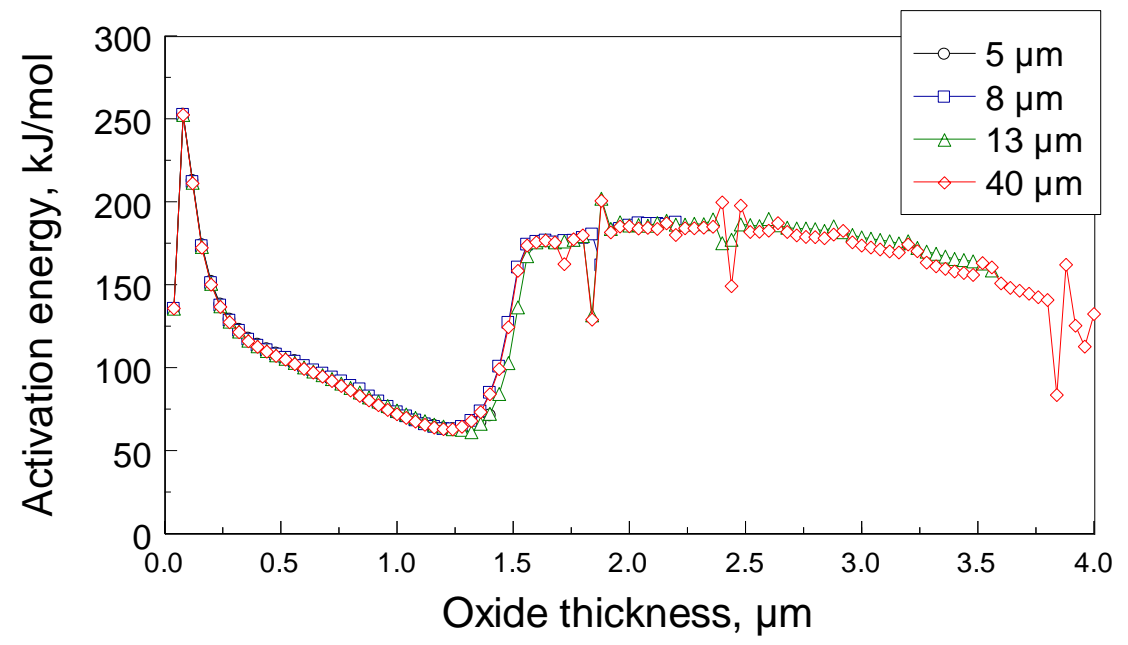

Figure 16. Apparent activation energy of oxidation for individual size bins of an Al-Mg alloy powder in oxygen as a function of reaction progress defined through the grown oxide thickness.

It remains unclear why the switch between the oxidation stages occurs at a specific oxide thickness. Relying on the data from XRD analyses (Fig. 6), the switch between the oxidation stages may be explained by the formation of the spinel phase, which happened to occur in the present experiments around $500{ }^{\circ} \mathrm{C}$ (Figs. 3, 9, 11), or when the oxide thickness was in the range of 1.24 and $1.56 \mu \mathrm{m}$. In previous work on pure aluminum oxidation [31], a similar stepwise oxidation process was attributed to the formation of $\gamma$ alumina, which has a disordered spinel structure. A different oxide structure causes different diffusivity, and thus provides a reasonable explanation for a changed reaction rate. In the case of Al-Mg alloys, $\mathrm{Al}-\mathrm{Mg}$ spinel forms instead of $\gamma$ alumina. Since there is no unambiguous indication that $\mathrm{Al}$ does not participate in the oxidation from the beginning, amorphous alumina is likely present on the particle surface. The formation of spinel from $\mathrm{MgO}$ and $\mathrm{Al}_{2} \mathrm{O}_{3}$ below a certain temperature is then possibly limited due to kinetic reasons. Indeed, the formation of $\mathrm{Al}-\mathrm{Mg}$ spinel from sol-gel precursors has been observed only above approximately $600{ }^{\circ} \mathrm{C}$ [32]. Elsewhere [33], it was observed that spinel forms after annealing to about $500{ }^{\circ} \mathrm{C}$ independent of the synthesis method. Formation of spinel nearly simultaneously for all powder particles at a threshold temperature may also explain why the activation energy obtained for the second stage of oxidation is nearly constant, at least while the oxide is growing up to about $3 \mu \mathrm{m}$. Indeed, continuing oxidation is driven by the inward diffusion of oxygen through a spinel layer for all particles. Thus, the activation energy of about $185 \mathrm{~kJ} / \mathrm{mol}$ characterizes diffusion of oxygen through a layer of $\mathrm{Al}_{2} \mathrm{MgO}_{4}$ spinel. The activation energy begins changing at greater thickness, most likely indicating a change in the particle shapes and particle sintering expected at high temperatures.

It should be emphasized that one important conclusion from this study, specifically, that the stepwise oxidation is not directly caused by selective $\mathrm{Mg}$ oxidation, strict or otherwise, could only be reached due to examination of individual particle sizes. Combination of the TG 
measurement with the particle size distribution is therefore essential when developing models for processes occurring on particle surfaces.

The current analysis could be improved in future work if the experimental parameters were varied more widely. This is most significant for wider particle size distributions. If the first oxidation step finishes due to spinel formation at a limiting temperature, then a particle of a larger size should exhibit the step even if its oxide layer has not reached the 1.2-1.5 $\mu \mathrm{m}$ determined in the current work. A similar argument can be made for extending the range of heating rates although that is more challenging experimentally. Finally, the issue of selective $\mathrm{Mg}$ oxidation could be further tested using alloy particles with different $\mathrm{Mg}$ concentrations.

\section{CONCLUSIONS}

The oxidation of both commercial spherical Al-Mg alloys and mechanically alloyed $\mathrm{Al}-\mathrm{Mg}$ powder in oxygen was investigated using thermo-gravimetry. The oxidation reaction consistently occurs at the interface between the metal alloy core and the oxide shell and thus is rate-limited by inward diffusion of oxygen ions. Voids are formed in the oxidized particles due to the redistribution of material within the metal core. Two oxidation stages were observed for both powders. Although the total mass change for the first stage and respective product phase analysis by XRD may be interpreted as showing selective Mg oxidation, analysis of the TG measurements using the particle size distribution for the spherical powder shows conclusively that this is not the case. Both $\mathrm{Al}$ and $\mathrm{Mg}$ oxidize during both observed oxidation stages. The second oxidation stage is caused by formation of the spinel phase, most likely occurring at a threshold temperature.

In the present measurements, the step in the oxidation rate, or switch between the oxidation stages, occurs when the oxide shell grows above a certain thickness of approximately $1.5 \mu \mathrm{m}$. However, this switch may be expected to occur at a different oxide thickness for alloys with different particle sizes, different compositions, or at significantly different heating rates. The apparent activation energy changes during the first oxidation stage suggesting that more than one reaction occur in parallel, e.g., causing formation of $\mathrm{MgO}$ and amorphous alumina. For the second oxidation step, the activation energy remains nearly constant around $185 \mathrm{~kJ} / \mathrm{mol}$ while the oxide shell grows up to approximately $3 \mu \mathrm{m}$. This activation energy characterized diffusion of oxygen through a spinel layer. At greater oxide thicknesses, a slow decrease in the apparent activation energy is observed, due to changes in morphology of the oxidizing powder.

\section{ACKNOWLEDGEMENT}

This work was supported by Defense Threat Reduction Agency 


\section{REFERENCES}

[1] G.S. Cole, A.M. Sherman, Light weight materials for automotive applications, Materials Characterization 35 (1995) 3-9.

[2] S. Toros, F. Ozturk, I. Kacar, Review of warm forming of aluminum-magnesium alloys, Journal of Materials Processing Technology 207 (2008) 1-12.

[3] A. Züttel, Hydrogen storage methods, Naturwissenschaften 91 (2004) 157-172.

[4] T.A. Roberts, R.L. Burton, H. Krier, Ignition and combustion of aluminum/magnesium alloy particles in O2 at high pressures, Combustion and Flame 92 (1993) 125-143.

[5] X.G. Wu, Q.L. Yan, X. Guo, X.F. Qi, X.J. Li, K.Q. Wang, Combustion efficiency and pyrochemical properties of micron-sized metal particles as the components of modified double-base propellant, Acta Astronautica 68 (2011) 1098-1112.

[6] E. Farbar, J. Louwers, T. Kaya, Investigation of metallized and nonmetallized hydroxyl terminated polybutadiene/hydrogen peroxide hybrid rockets, Journal of Propulsion and Power 23 (2007) 476-486. [7] M.H. Zayan, O.M. Jamjoom, N.A. Razik, High-temperature oxidation of Al-Mg alloys, Oxidation of Metals 34 (1990) 323-333.

[8] P. Krizik, M. Balog, E. Illekova, P. Svec Sr, I. Matko, M. Stepanek, M. Nosko, F. Simancik, The oxidation behavior of gas-atomized $\mathrm{Al}$ and $\mathrm{Al}$ alloy powder green compacts during heating before hot extrusion and the suggested heating process, Journal of Materials Processing Technology 214 (2014) 1165-1172. [9] C. Lea, J. Ball, The oxidation of rolled and heat treated Al-Mg alloys, Applications of Surface Science 17 (1984) 344-362.

[10] J.D. Moretti, J.J. Sabatini, G. Chen, Periodate Salts as Pyrotechnic Oxidizers: Development of Barium- and Perchlorate-Free Incendiary Formulations, Angew. Chem., Int. Ed. 51 (2012) 6981-6983.

[11] H. Habu, Application of magnalium to solid rocket propellant, Keikinzoku 58 (2008) 162-166.

[12] H. Habu, K. Hori, The burning rate characteristics of magnalium (Mg/Al)-AP based solid propellant, Science and Technology of Energetic Materials 67 (2006) 187-192.

[13] H. Murata, Y. Azuma, T. Tohara, M. Simoda, T. Yamaya, K. Hori, T. Saito, Effect of magnalium (Mg-Al alloy) on combustion characteristics of ammonium nitrate-based solid propellant, Kayaku Gakkaishi/Journal of the Japan Explosives Society 61 (2000) 58-66.

[14] M.N. De Noirfontaine, G. Baldinozzi, M.G. Barthés-Labrousse, J. Kusinski, G. Boëmare, M. Herinx, M. Feuerbacher, High temperature oxidation of the Al 3Mg 2 complex metallic alloy, Oxidation of Metals 73 (2010) 219-232.

[15] N.B. Pilling, R.E. Bedworth, The Oxidation of Metals at High Temperatures, Journal of the Institute of Metals 29 (1923) 529-591.

[16] H. Nie, S. Zhang, M. Schoenitz, E.L. Dreizin, Reaction interface between aluminum and water, International Journal of Hydrogen Energy 38 (2013) 11222-11232.

[17] S. Zhang, E.L. Dreizin, Reaction interface for heterogeneous oxidation of aluminum powders, Journal of Physical Chemistry C 117 (2013) 14025-14031.

[18] H. Nie, M. Schoenitz, E.L. Dreizin, Oxidation of magnesium: implication for aging and ignition, The Journal of Physical Chemistry C in press (2016).

[19] Y. Aly, M. Schoenitz, E.L. Dreizin, Ignition and combustion of mechanically alloyed Al-Mg powders with customized particle sizes, Combustion and Flame 160 (2013) 835-842.

[20] Y. Aly, V.K. Hoffman, M. Schoenitz, E.L. Dreizin, Preparation, ignition, and combustion of mechanically alloyed Al-Mg powders with customized particle sizes, Materials Research Society Symposium Proceedings, 2013, pp. 43-48.

[21] Y. Aly, V.K. Hoffman, M. Schoenitz, E.L. Dreizin, Reactive, mechanically alloyed Al · Mg powders with customized particle sizes and compositions, Journal of Propulsion and Power 30 (2014) 96-104. 
[22] H. Nie, M. Schoenitz, E.L. Dreizin, Initial stages of oxidation of aluminum powder in oxygen, Journal of Thermal Analysis and Calorimetry in press (2016).

[23] W.M. Haynes, CRC Handbook of Chemistry and Physics, 92nd Edition, CRC Press2011.

[24] O. Anderson, Equations of State for Solids in Geophysics and Ceramic Science, Oxford University Press1995.

[25] W. Kollenberg, J. Margalit, Thermal expansion of AION and $y$-Al2O3, Journal of Materials Science Letters 11 (1992) 991-993.

[26] P. Šimon, Isoconversional methods: Fundamentals, meaning and application, Journal of Thermal Analysis and Calorimetry 76 (2004) 123-132.

[27] A. Khawam, D.R. Flanagan, Role of isoconversional methods in varying activation energies of solidstate kinetics: II. Nonisothermal kinetic studies, Thermochimica Acta 436 (2005) 101-112.

[28] J.D. Peterson, S. Vyazovkin, C.A. Wight, Kinetics of the thermal and thermo-oxidative degradation of polystyrene, polyethylene and poly(propylene), Macromolecular Chemistry and Physics 202 (2001) 775784.

[29] S. Vyazovkin, A.K. Burnham, J.M. Criado, L.A. Pérez-Maqueda, C. Popescu, N. Sbirrazzuoli, ICTAC Kinetics Committee recommendations for performing kinetic computations on thermal analysis data, Thermochimica Acta 520 (2011) 1-19.

[30] S. Vyazovkin, Modification of the Integral Isoconversional Method to Account for Variation in the Activation Energy, Journal of Computational Chemistry 22 (2001) 178-183.

[31] M.A. Trunov, M. Schoenitz, E.L. Dreizin, Effect of polymorphic phase transformations in alumina layer on ignition of aluminium particles, Combustion Theory and Modelling 10 (2006) 603-623.

[32] P. Kirszensztejn, R. Przekop, A. Szymkowiak, E. MaćKowska, J. Gaca, Preparation of MgO-Al2O3 binary gel system with mesoporous structure, Microporous and Mesoporous Materials 89 (2006) 150157.

[33] C. Păcurariu, I. Lazău, Z. Ecsedi, R. Lazău, P. Barvinschi, G. Mărginean, New synthesis methods of MgAl2O4 spinel, Journal of the European Ceramic Society 27 (2007) 707-710. 